\title{
SYNTHESIS OF HIERARCHICAL TS-1 ZEOLITE FROM SILANIZED SEEDS
}

D. P. Serrano a,b, R. Sanz ${ }^{a}$, P. Pizarro ${ }^{a}$ I. Moreno ${ }^{a}$

aDepartment of Chemical and Energy Technology, ESCET, Universidad Rey Juan Carlos 'IMDEA Energía

c/ Tulipán s/n, 28933 Móstoles, Madrid, Spain

e-mail: david.serrano@urjc.es

Published on:

“Topics in Catalysis" Volume 53, Numbers 19-20, pag. 1319-1329.

DOI: $\underline{10.1007 / s 11244-010-9590-9}$

\begin{abstract}
Hierarchical TS-1 zeolites with a bimodal pore architecture, consisting of the typical MFI micropores and an additional mesoporosity, have been synthesized by grafting an organosilane compound to the zeolitic seeds previously prepared from two different raw materials: a liquid gel and an amorphous $\mathrm{SiO}_{2}-\mathrm{TiO}_{2}$ xerogel. These hierarchical TS-1 zeolites show an excellent catalytic behavior in olefin epoxidation reactions employing organic hydroperoxides as oxidants due to the presence of the secondary mesoporosity, which makes possible the access and interaction of bulky molecules with the Ti active sites.
\end{abstract}

\section{Keywords}

TS-1 zeolite, hierarchical porosity, epoxidation, hydroperoxides 


\section{Introduction}

Microporous zeolites are widely used as heterogeneous catalysts, especially in petroleum refining, fine-chemistry and pharmaceutical industry due to their excellent catalytic properties such as high surface area, tunable pore size and high thermal stability $[1,2]$. Likewise, microporous zeolites are significantly more active than layered structures (clays) or amorphous mesoporous materials [2]. However, this microporosity hinders the use of zeolites as catalysts for reactions involving bulky molecules. Moreover, intracrystalline diffusion often takes place at low rate, limiting also their potential applications [3]. For these reasons, many efforts have been carried out during the past years in order to overcome the diffusional and steric restrictions of zeolites. In this context, hierarchical zeolites have emerged as a new type of materials characterized by having, additionally to the zeolitic micropores, a secondary porosity in the meso/macroporous range with higher accessibility and capability to catalyze reactions involving bulky molecules [4]. This additional porosity may be intercrystalline, as a consequence of zeolite nanocrystals packing, or intracrystalline, when zeolite crystals exhibit a non-crystallographic meso/macroporous system in addition to the zeolitic one.

The generation of this secondary porosity in zeolites has been accomplished utilizing different strategies, which can be classified in two groups: templated or non-templated routes. The latter includes a variety of methods such as post-synthesis treatments of steaming, acid or basic leaching and those based on the synthesis of clear gels under experimental conditions which favors nucleation over crystal growth [5]. On the other hand, templated methods employ different structures to tailor the pore size and geometry of the hierarchical porosity: hard templates (solids) and soft templates (supramolecular structures). A relatively large variety of materials have been reported as hard templates, such as porous carbons [6], carbon nanotubes [7], polystyrene beads [8], cationic polymers 
[9], wood cells [10], diatoms [11], etc. while different surfactants have been employed as soft templates [12-15].

Recently, a new synthesis strategy has been developed to obtain hierarchical zeolites based on the use of organosilanes to prevent the growth of zeolitic seeds. This strategy can be considered as a general route since it has been successfully applied to the synthesis of a variety of zeolites such as ZSM-5, ZSM-11, Beta, Mordenite, etc [16-18].

TS-1 (Titanium Silicalite-1) zeolite, discovered by Taramasso and coworkers in 1983 [19], is a molecular sieve with MFI structure, characterized by the presence of isolated titanium atoms into the zeolite framework. This isomorphical substitution of Si by Ti atoms provides the TS-1 zeolite with a remarkable catalytic activity in the selective oxidation of a variety of organic substrates: olefins to epoxides, alcohols to aldehydes or ketones, hydroxylation of aromatic compounds and the ammoximation of cyclohexanone [20-22]. Since the pore size of TS-1 zeolite is too small to allow bulky reactants to diffuse towards the active sites located within the zeolitic micropores, this material is usually associated to the use of hydrogen peroxide as oxidant, whereas it is almost completely inactive when employing organic hydroperoxides due to their relatively large size [23]. However, the use of organic hydroperoxides as oxidants is of great interest as it would enable to carry out reactions in water-free media, which is an important aspect when the presence of water can be detrimental for the selectivity towards the target products [24]. In order to overcome these limitations, the preparation of hierarchical TS-1 zeolite has been attempted in the literature through different strategies. Thus, mesoporous TS-1 crystals have been obtained using hard templates as carbon black and CMK-3 $[25,26]$.

In the present, hierarchical TS-1 zeolites have been prepared by organofunctionalization of zeolitic seeds and further crystallization. The physicochemical and catalytic properties of hierarchical TS-1 samples obtained by application of this strategy to two different synthesis 
routes (from liquid gels and amorphous $\mathrm{SiO}_{2}-\mathrm{TiO}_{2}$ xerogels) are compared with those exhibited by standard TS-1 samples.

\section{Experimental}

\subsection{Synthesis of hierarchical TS-1 zeolites}

Hierarchical TS-1 zeolitic materials were obtained following a synthesis strategy based on the silanization of zeolitic seeds. This method involves precrystallizacion and silanization steps, prior to the hydrothermal crystallization treatment. Two different synthesis gels were used as starting materials: a) liquid gels and b) amorphous $\mathrm{SiO}_{2}-\mathrm{TiO}_{2}$ xerogels. A detailed description of both synthesis procedures is presented below:

a) Synthesis of hierarchical TS-1 zeolite from liquid gels

This sample was obtained by adapting the original recipe developed by Taramasso et al. [19], using tetraethylorthosilicate (TEOS, Alfa) and tetraethylorthotitanate (TEOT, Alfa) as silica and titanium precursors, respectively. In a typical synthesis, both inorganic precursors were completely mixed at $30^{\circ} \mathrm{C}$. Afterwards, the mixture was cooled at $0^{\circ} \mathrm{C}$ and a $1 \mathrm{M}$ TPAOH aqueous solution was added dropwise. The resultant solution was heated at $80^{\circ} \mathrm{C}$ in order to evaporate the ethanol generated during the hydrolysis of the titanium and silica precursors. The molar composition of the final gel so obtained was as follows: $\mathrm{SiO}_{2}$ : $0.0163 \mathrm{TiO}_{2}: 0.44 \mathrm{TPAOH}: 28.5 \mathrm{H}_{2} \mathrm{O}$. After that, this solution was precrystallized in a reflux system under stirring conditions at $90^{\circ} \mathrm{C}$ for 24 hours. In a further step, the functionalization reaction was carried out under stirring at $90^{\circ} \mathrm{C}$ for 6 hours by addition of the silanization agent, phenylaminopropyltrimethoxisilane (PHAPTMS, Aldrich), with a loading of $8 \mathrm{~mol} \%$ referred to the total silica content in the gel. Finally, the crystallization of the TS- 1 zeolite was carried out by microwave heating at $170{ }^{\circ} \mathrm{C}$ for 8 hours in teflon vessels under autogenous pressure. The sample so obtained was denoted as TS-1 (LG-8 \%). 
b) Synthesis of hierarchical TS-1 zeolite from amorphous $\mathrm{SiO}_{2}-\mathrm{TiO}_{2}$ xerogels

The amorphous $\mathrm{SiO}_{2}-\mathrm{TiO}_{2}$ xerogel used as raw material was synthesized by a sol-gel method comprising two steps [27]. Firstly, the acid hydrolysis of silica and titanium sources, tetraethylorthosilicate (TEOS, Alfa) and titanium tetrabutoxide (TNBT, Acros), respectively, was carried out employing a $0.05 \mathrm{M} \mathrm{HCl}$ aqueous solution and a $\mathrm{H}_{2} \mathrm{O} / \mathrm{TEOS}$ molar ratio of 4 . Secondly, a $1 \mathrm{M}$ aqueous solution of tetrapropylammonium hydroxide (TPAOH) was added dropwise until reaching the gel point. The cogel so obtained was dried at $110^{\circ} \mathrm{C}$ during 24 hours. The final molar composition of this raw xerogel was as follows: $1.0 \mathrm{SiO}_{2}: 0.016 \mathrm{TiO}_{2}: 0.0355 \mathrm{TPAOH}$. Once the $\mathrm{SiO}_{2}-\mathrm{TiO}_{2}$ xerogel was obtained, it was impregnated with a $1 \mathrm{M}$ TPAOH aqueous solution employing a TPAOH/xerogel mass ratio of 2.75 . The impregnated xerogel was precrystallized at $120^{\circ} \mathrm{C}$ by heating with microwave radiation for 2 hours. Thereafter, an additional amount of $1 \mathrm{M} \mathrm{TPAOH}$ solution was added to the system in order to increase the TPAOH/xerogel mass ratio from 2.75 to 3.5. At the same time the silanization agent, PHAPTMS, was added in a concentration of 5 mol\% referred to the total silica content in the raw xerogel. Thus, the silanization reaction was performed under reflux with stirring at $90^{\circ} \mathrm{C}$ for six hours. Finally, the hydrothermal crystallization step was carried out by microwave heating at $170^{\circ} \mathrm{C}$ for 8 hours in teflon vessels under autogenous pressure. The hierarchical TS-1 sample so prepared was designated as TS-1 (XG-5\%).

c) Synthesis of TS-1 reference samples

Two references TS-1 zeolites were synthesized following the procedures above described but omitting both the precrystallization and the silanization stages. They were denoted as TS-1 (LG-REF) and TS-1 (XG-REF), respectively. Likewise, a reference sample, designated as TS-1 (LG-PC), was prepared from a liquid gel including the precrystallization treatment at $90{ }^{\circ} \mathrm{C}$ but omitting the silanization step. 
In all cases, the solid products obtained after the crystallization treatments were separated by centrifugation, washed several times with distilled water, dried overnight at $110{ }^{\circ} \mathrm{C}$ and calcined in air at $550{ }^{\circ} \mathrm{C}$ for $5 \mathrm{~h}$.

\subsection{Characterization techniques}

All the TS-1 samples were characterized by different techniques. X-Ray Diffraction (XRD) patterns were collected on a Philips X'PERT MPD diffractometer employing CuK $\alpha$ radiation using a step size of $0.02^{\circ}$ and a counting time of $10 \mathrm{~s}$, respectively, from $5-50^{\circ}$. The coordination of the titanium atoms was determined by Diffuse Reflectance UV-Vis spectroscopy (DR UV-Vis) using a VARIAN CARY-500 spectrophotometer equipped with a diffuse reflectance accessory. Titanium contents of the calcined samples were estimated by means of Atomic Emission Spectroscopy with Induced Coupled Plasma (ICP-AES) using a Varian Vista AX instrument. The organic content of the as-synthesized samples was determined by elemental analyses performed on a CHNS Elementar Vario EL III analyzer. Transmission Electronic Microscopy (TEM) images were recorded on a Philips Technai 20 microscope operating at $200 \mathrm{kV}$. Ar adsorption-desorption isotherms were measured by a Micromeritics ASAP 2010 instrument at $87.35 \mathrm{~K}$, the sample being previously degassed at $573 \mathrm{~K}$ for 10 hours by means of a turbomolecular pump. The total surface area was estimated according to the BET method, whereas the pore size distribution and the cumulative volume curves were calculated by applying the NL-DFT model assuming cylindrical pore geometry.

\subsection{Catalytic tests}

The catalytic behavior of the hierarchical TS-1 zeolites was evaluated by means of olefin epoxidation reactions, using both hydrogen peroxide $\left(\mathrm{H}_{2} \mathrm{O}_{2}, 30 \%\right.$ Sharlau) and tertbutylhydroperoxide (TBHP, $5.5 \mathrm{M}$ in decane, Fluka) as oxidants. 
In a typical experiment with hydrogen peroxide as oxidant, $300 \mathrm{mmol}$ of acetone (Sharlau), $50 \mathrm{mmol}$ of 1-octene (Aldrich) and $0.4 \mathrm{~g}$ of catalyst were added into a $250 \mathrm{ml}$ round bottom flask and heated at $60^{\circ} \mathrm{C}$ for 3 hours under stirring conditions and atmospheric pressure. The oxidant solution, which consisted in $30 \mathrm{mmol}$ of acetone and $8 \mathrm{mmol}$ of $\mathrm{H}_{2} \mathrm{O}_{2}$, was progressively added at 0,1 and 2 hours from the beginning of the reaction.

The reactions performed with TBHP as oxidizing agent were carried out utilizing $30 \mathrm{mmol}$ of olefin, $35 \mathrm{mmol}$ of TBHP and $0.2 \mathrm{~g}$ of catalyst. These experiments were performed in a round bottom flask at $100^{\circ} \mathrm{C}$ for 3 hours under stirring conditions and atmospheric pressure. In this case, both 1-octene and cyclohexene were used as substrates.

In all the experiments, the reactants and products were analyzed by gas chromatography (capillary column $60 \mathrm{~m} \times 0.25 \mathrm{~mm}$, VARIAN FFAP, FID detector) using toluene (Sharlab) as internal standard. Both $\mathrm{H}_{2} \mathrm{O}_{2}$ and TBHP conversions were determined by standard iodometric titration.

\section{Results and discussion}

In this work, we report a comparative study of the physicochemical and catalytic properties of hierarchical TS-1 zeolites obtained by organofunctionalization of zeolitic seeds using two different procedures starting from a liquid gel (LG) and a $\mathrm{SiO}_{2}-\mathrm{TiO}_{2}$ amorphous xerogel $(\mathrm{XG})$, respectively, as raw materials for the crystallization. In both cases, precrystallization and silanization steps were carried out prior to the hydrothermal crystallization. The precrystallization treatment is aimed to the formation of TS-1 seeds. Subsequently, the silanization agent, phenylaminopropyltrimethoxysilane (PHAPTMS), is reacted with the surface hydroxyl groups of TS-1 proto-zeolitic entities formed during the precrystallization step. The functionalization by the organosilane compound generates a protective barrier hindering the aggregation of the zeolitic seeds and, hence, disturbing the 
crystal growth during the final crystallization stage. Finally, when the organic molecules are removed by calcination, the space initially occupied by the organosilane leads to the formation of a secondary porosity.

Wide-angle XRD patterns of both as-synthesized hierarchical and reference TS- 1 zeolites are shown in Figure 1. As it can be clearly observed, all the samples exhibit the typical diffraction peaks corresponding to the MFI zeolitic structure denoting a high crystallinity degree. However, the spectra corresponding to the materials prepared from silanized seeds, as well as that of the sample obtained by a precrystallization-crystallization process [TS-1 (LG-PC)], exhibit less intense reflections than the reference zeolites, suggesting that a size reduction of the crystalline domains has occurred.

The high crystallinity of these samples is also corroborated by the presence of a welldefined band at $550 \mathrm{~cm}^{-1}$ in the FT-IR spectra (Figure 2). Likewise, the existence of a band at $960 \mathrm{~cm}^{-1}$, commonly assigned to the stretching vibration of [ $\left.\mathrm{SiO}_{4}\right]$ units linked to $\mathrm{Ti}$ atoms, indicates that the $\mathrm{Ti}$ atoms have been incorporated into the zeolite framework. Moreover, a very broad band in the $3200-3600 \mathrm{~cm}^{-1}$ region is observed. This band, associated to the presence of water molecules adsorbed on surface hydroxyl groups, is more intense in the FT-IR analyses obtained for the hierarchical TS-1 materials, which could be related with a decrease in size of the crystalline domains. This higher concentration of hydroxyl groups is expected to provide these samples with a higher hydrophilic character.

Table 1 summarizes the crystallization yields and the composition of the synthesized zeolitic materials. All the samples present titanium contents close to $1 \mathrm{wt} \%$, which is the amount initially incorporated into the synthesis gel. Concerning the solid yield, it is higher for the samples prepared from silanized seeds than for the reference zeolites, this effect being more pronounced for the samples prepared from liquid gels. This fact can be 
attributed to the increase in the synthesis times that take place when running precrystallization and silanization stages. Moreover, it must be taken into account that, as a consequence of the silanization treatment, one silicon atom is incorporated per mol of organosilane compound, which in turn also contributes to enhanced solid yields. On the other hand, the zeolite prepared from a liquid gel including solely a precrystallizationcrystallization process [TS-1 (LG-PC)] shows the lowest yield value, which it is probably due to the higher difficulty observed in its recovery by centrifugation. Finally, the synthesis yields corresponding to the samples obtained from amorphous $\mathrm{SiO}_{2}-\mathrm{TiO}_{2}$ xerogels were higher than those of the zeolites prepared from liquid gels. This fact can be related with the different crystallization mechanism that occurs in each case. As it has been earlier reported [28], the crystallization of TS-1 zeolite prepared from amorphous xerogels takes place mainly by the reorganization of the raw amorphous material through solid-solid transformations. This mechanism is in contrast with the conventional mechanism in which the initial solid crystalline units are formed from a clear solution.

Diffuse Reflectance UV-Vis spectroscopy was employed in order to determine the environment of the $\mathrm{Ti}$ atoms and, consequently, to confirm the incorporation of the $\mathrm{Ti}$ species into the zeolite framework. It is well known that the Ti species substituting silicon atoms in the zeolite framework are the active sites for catalytic oxidations of hydrocarbons using peroxides as oxidants. Moreover, the existence of extra-framework $\mathrm{TiO}_{2}$ has been proved to be detrimental for the catalytic performance. The DR UV-Vis spectra corresponding to calcined TS-1 materials are depicted in Figure 3. All the samples show a relatively sharp and narrow absorption band at $215-220 \mathrm{~nm}$, indicative of the presence of $\mathrm{Ti}$ atoms in a tetrahedral coordination. However, both the TS- 1 materials prepared from silanized seeds and the sample TS-1 (LG-PC) exhibit a broader band which spreads out to 
$260-280 \mathrm{~nm}$. This absorption is attributed to the presence of isolated Ti atoms in penta- or hexahedral coordination, which is probably caused by an increase of the concentration of surface hydroxyl groups, as they lead to a higher hydration capacity [29, 30]. Moreover, sample TS-1 (LG-PC), synthesized by a precrystallization-crystallization process, shows a slight absorption at approximately $330 \mathrm{~nm}$ revealing the existence of a small proportion of extra-framework $\mathrm{TiO}_{2}$. However, this band is absent in the TS-1 samples prepared by crystallization of silanized seeds, denoting the high quality of these materials.

TEM images corresponding to TS- 1 samples obtained from liquid gels are depicted in Figure 4. Sample TS-1 (LG-REF) is comprised by regular crystals with mean dimensions around $200 \mathrm{~nm}$, exhibiting well defined edges. This morphology and size are consistent with those typical of conventional TS-1 prepared from liquid gels. On the other hand, the sample prepared by a precrystallization-crystallization procedure, TS-1 (LG-PC), consists of irregular polycrystalline particles with sizes around 80-100 nm. These particles are formed by aggregation of smaller crystals with dimensions ranging from 40 to $60 \mathrm{~nm}$, revealing that a decrease in the nanocrystal size occurs just incorporating a precrystallization step. Accordingly, sample TS-1 (LG-PC) can be considered as a nanocrystalline zeolite sample. This fact can be attributed to the modification of the crystallization process produced when a precrytallization step at low temperature is carried out before the crystallization treatment, performed at $170{ }^{\circ} \mathrm{C}$. When the zeolite synthesis is performed with just one step at high temperature, both nucleation and crystal growth occur almost simultaneously [28]. However, when a precrystallization step at low temperature is introduced in the synthesis procedure, the crystallization occurs with a clear separation of nucleation and crystal growth. As a consequence, nucleation is favored leading to the generation of a higher 
concentration of nuclei and, subsequently, to the formation of smaller crystals with size within the nanometer range $(<100 \mathrm{~nm})$.

In the case of the sample obtained by silanization of zeolitic seeds, TS-1 (LG-8 \%), it consists in slightly larger aggregates than TS-1 (LG-PC), with sizes in the range of 100-150 nm and sponge-like morphology. From images taken at higher magnifications it may be distinguished that these aggregates are formed by ultra small crystalline domains with dimensions below 20-25 $\mathrm{nm}$. The presence of diffraction fringes in these units confirms their crystalline nature. This result confirms that the organosilane compound anchored over the zeolitic seeds surface (amorphous solid nanounits formed in the precrystallization stage) acts as a barrier for their growth and aggregation during the crystallization treatment. Therefore, the dimensions of the nanocrystalline units in the silanized seed samples are lower than in the material prepared by a precrystallization-crystallization process.

TEM images corresponding to the samples prepared from $\mathrm{SiO}_{2}-\mathrm{TiO}_{2}$ xerogels, shown in Figure 5, indicate that both the morphology and size of the crystals are different to those corresponding to TS-1 zeolites obtained from liquid gels. Thus, the reference TS-1 (XG-REF) zeolite is formed by particles with an average dimension of around $2 \mu \mathrm{m}$, which is much larger than the size of TS-1 (LG-REF) crystals. In the case of the zeolite obtained from xerogels including the seed silanization treatment (TS-1 (XG-5\%), the particle size is quite smaller with values around 250-300 $\mathrm{nm}$. Moreover, these particles are not isolated but they are grouped into aggregates. TEM micrographs taken at higher magnifications reveal the polycrystalline nature of these particles, which are formed by a tight packing of interconnected nanocrystals. The different morphology and dimensions exhibited for the samples prepared from amorphous $\mathrm{SiO}_{2}-\mathrm{TiO}_{2}$ xerogels and the samples obtained from 
liquid gels is related to the different crystallization mechanism followed when the starting material is either an amorphous solid or a clear solution.

Figure 6 illustrates the Ar adsorption-desorption isotherms, measured at $87.3 \mathrm{~K}$, corresponding to different TS-1 samples, while Table 2 summarizes the main textural properties determined by applying the NL-DFT method. Szm and Vzm refer to the surface area and pore volume, respectively, of the zeolitic micropores, while SSP and VSP correspond to these properties when they are associated to the secondary porosity. Note that this secondary porosity includes also the contribution of both the external surface and voids generated between the crystalline domains.

The reference zeolites, TS-1 (LG-REF) and TS-1 (XG-REF), exhibit type I isotherms according to the IUPAC classification, with a strong and sharp adsorption at low relative pressures, as it corresponds to the uniform microporosity characteristic of the MFI structure. Likewise, these samples present similar BET surface area and Vzm values, with values around $450 \mathrm{~m}^{2} / \mathrm{g}$ and $0.2 \mathrm{~cm}^{3} / \mathrm{g}$, respectively, which agrees well with those corresponding to conventional TS-1 samples. The of TS-1 (LG-PC) sample, prepared from a liquid gel using a combination of precrystallization and crystallization processes, exhibits a shape similar to that of the reference materials at $\mathrm{P} / \mathrm{P}_{0}$ values lower than 0.15 . However, the isotherm changes at higher relative pressures with a sharp adsorption step at relative pressures above 0.8 , which is accompanied by a hysteresis loop. This behavior is typical of materials having interparticle porosity, which in this case is consistent with the sample being formed by nanocrystals as earlier concluded from the TEM images.

Concerning the TS-1 samples prepared from silanized seeds, a strong increase in the Ar adsorption is observed when compared with the corresponding reference zeolites. Likewise, a significant increase in the value of the different textural properties is denoted. 
Thus, for the TS-1 (LG-8\%) sample, SBET and Ssp reach values of 606 and $349 \mathrm{~m}^{2} / \mathrm{g}$, respectively, whereas the value of the volume of the secondary porosity (Vsp) is $0.29 \mathrm{~cm}^{3} / \mathrm{g}$. It is noteworthy that, for this sample, the surface area associated to the secondary porosity represents almost $60 \%$ of the total BET surface.

The application of the NL-DFT model also allows the pore size distribution in the micro and mesopore region to be estimated as a continuous function. Figure 7 shows the results so obtained for the different samples in the form of cumulative pore volume and pore size distribution (PSD) versus the size of the pores, calculated assuming cylindrical pore geometry. In all cases, a narrow peak with a maximum around $0.52 \mathrm{~nm}$ is detected in the PSD curves, which agrees well with the size of the MFI micropores. In the case of TS-1 (LGPC) sample, prepared from a liquid gel by means of a precrystallization-crystallization process, an additional peak is located at around $30 \mathrm{~nm}$, originated from the voids existing between the zeolite nanocrystals.

The presence of a secondary porosity is also clearly observed for the TS- 1 materials prepared from silanized seeds. For both samples the curves of the cumulative pore volume show an important enhancement of the adsorption associated to pores larger than the zeolite micropores. This fact leads to the appearance of relatively broad peaks in the PSD within the supermicro- and mesopore ranges. In the case of the sample obtained from a liquid gel this secondary porosity is more pronounced, with a peak maximum centered at $3.5 \mathrm{~nm}$, than that of the TS-1 material obtained from a xerogel. These results demonstrate clearly the presence of a secondary porosity in the samples obtained from silanized seeds and confirm that the incorporation of the silanization step prevents partially the aggregation and fusion of the zeolite nanounits causing the formation of zeolites with hierarchical porosity and enhanced textural properties. 
The catalytic behavior of the different TS-1 samples was initially studied in 1-octene epoxidation using hydrogen peroxide as oxidazing agent. The resultant substrate conversion $\left(\mathrm{X}_{1-\mathrm{OCTENE}}\right)$, turnover frecuency $(\mathrm{TOF})$ and the oxidant efficiency are summarized in Table 3. In all the experiments, the selectivity towards the epoxide was $100 \%$ since no other products were detected. The highest conversion and turnover frequency values were obtained for the reference zeolites, TS-1 (LG-REF) and TS-1 (XG-REF), reaching values close to $12 \%$ and $20 \mathrm{~h}^{-1}$, respectively. In contrast the nanocrystalline and hierarchical TS-1 samples present significantly lower conversion and TOF values. It should be noted that the catalytic activity seems to decrease in these samples as the surface area related to the secondary porosity (Ssp) increases. This result indicates that the generation of hierarchical porosity and nanocrystalline features in TS-1 zeolite is detrimental for its catalytic performance when using hydrogen peroxide as oxidant. Since no great changes are observed in the oxidant efficiency, these negative results cannot be attributed to the $\mathrm{H}_{2} \mathrm{O}_{2}$ decomposition. As it was previously commented, a reduction of the hydrophobic nature of the zeolite surface takes place due to the increase of the amount of surface hydroxyl groups located on the external and the mesopore surface areas. Consequently, it is expected that the water molecules, added to the reaction media together with the hydrogen peroxide, are adsorbed on the non-microporous zeolite surface, hindering the access of the organic substrate to the Ti active sites [31].

Based on the previous finding, it was concluded that the catalytic behavior of these samples should be different if the reactions were carried out in a water-free reaction system. In order to check this assumption, epoxidation reactions of either 1-octene or cyclohexene were carried out using an organic peroxide (tertbutylhydroperoxide, TBHP) as oxidant, the results obtained being summarized in Table 4 . In all cases, the selectivity 
towards the corresponding epoxides were again $100 \%$ and the efficiencies in the use of the oxidant were in most cases also very high, over $90 \%$, quite superior to those obtained in the reactions using hydrogen peroxide. Just in the case of sample TS-1 (LG-PC) a somewhat lower TBHP efficiency was obtained. Moreover, for all the TS-1 samples the conversions obtained in the cyclohexene epoxidation were quite larger than those of 1-octene, which is due to the higher reactivity of the former substrate.

Interestingly, in the epoxidation reactions carried out with TBHP, the reference TS-1 (LGREF) and TS-1 (XG-REF) samples were the catalysts exhibiting the lowest conversion with both substrates. This behavior is completely the opposite to that observed when using hydrogen peroxide, pointing out the strong limitations that TS- 1 zeolite suffers for reactions using organic peroxides as the latter cannot enter into the zeolite micropores, fact that it is well known in the literature. In contrast, the catalytic activity of the hierarchical TS-1 samples was several times higher than those obtained with the reference ones. On the other hand, the TS-1 (LG-PC) sample possesses a catalytic activity intermediate between those corresponding to reference and hierarchical materials.

The strong improvement of the catalytic activity for the hierarchical TS- 1 samples is attributed to the enhanced accessibility of both substrate and oxidant molecules to the $\mathrm{Ti}$ active sites, provided by the existence of an additional mesoporosity. It is interesting to note that the highest catalytic activity was obtained for the sample TS-1 (LG-8 \%), prepared by silanization of zeolitic seeds employing a liquid gel as starting material. Thus, 1-octene and cyclohexene conversions obtained with this catalyst were $42.1 \%$ and $85.3 \%$, respectively, while the reference sample TS-1 (LG-REF) achieved conversion percentages of just $6.7 \%$ and $22.0 \%$, respectively, and TS-1 (XG-5\%) exhibited conversion values of 26.4 $\%$ and $65.2 \%$, respectively. These results confirm, in line with the previous characterization 
data, that the seed silanization treatment has a more remarkable effect when the zeolitic material is obtained from liquid gels than when it is prepared from $\mathrm{SiO}_{2}-\mathrm{TiO}_{2}$ xerogels.

With the aim of checking the relationship between catalytic activity and the enhancement of the accessibility to the Ti sites, the turnover frequency (TOF) obtained with the different catalysts using TBHP as oxidant has been represented versus the surface area associated to the secondary porosity in Figure 8 . For both olefins, a direct an almost linear trend can be observed, confirming the strong positive effects induced by the secondary porosity. Moreover, this linear relationship suggests that the active sites for epoxidation with TBHP are mainly those $\mathrm{Ti}$ centers located outside the zeolite micropores, i.e. Ti sites on the external surface of the crystals or on the surface associated to the secondary porosity, while the role played by the Ti sites located inside the zeolitic micropores would be negligible as a consequence of the steric and diffusional limitations suffered by the TBHP molecules.

\section{Conclusions}

The seed silanization approach has been successfully applied for the preparation of hierarchical TS-1 materials starting from either liquid gels or $\mathrm{SiO}_{2}-\mathrm{TiO}_{2}$ xerogels. The incorporation of precrystallization and silanization steps, prior to the conventional hydrothermal crystallization treatment, leads to materials exhibiting a hierarchical porosity comprised by a typical microporous zeolitic system and an additional porosity in the range of supermicropore/mesopores.

Although the main physicochemical properties, such as crystallinity, Ti content or Ti atoms environment are similar in both cases, the nature of the starting material (liquid gel or xerogel) have a remarkable effect in the textural properties. The material obtained from liquid gels present an enhanced surface area (SвEт of $606 \mathrm{~m}^{2} / \mathrm{g}$ ), quite higher than SвEt 
values corresponding to the TS-1 reference zeolites and also superior to that of the sample prepared from amorphous $\mathrm{SiO}_{2}-\mathrm{TiO}_{2}$ xerogels $\left(564 \mathrm{~m}^{2} / \mathrm{g}\right)$. This difference is even more pronounced for the values of surface area associated to the secondary porosity (SsP): 349 $\mathrm{m}^{2} / \mathrm{g}$ (LG-8 \%), $270 \mathrm{~m}^{2} / \mathrm{g}$ (XG-5 \%) and below $80 \mathrm{~m}^{2} / \mathrm{g}$ for the reference samples.

Since the generation of the secondary porosity on the hierarchical TS- 1 zeolites is accompanied by an increase of the surface hydrophilic character due to a higher concentration of hydroxyl groups, these zeolites exhibit lower catalytic activities than conventional TS- 1 reference materials in epoxidation reactions using $\mathrm{H}_{2} \mathrm{O}_{2}$ as oxidant. In contrast, the catalytic activity of the hierarchical TS-1 zeolites is much better than those of the conventional TS-1 zeolites when bulky organic oxidants, like TBHP, are employed in water-free media. In this case, high conversions of the epoxide are obtained due to the higher accessibility to the active sites.

A linear relationship has been found in olefin epoxidation (1-octene and cyclohexene) with TBHP between the catalytic activity and the surface area corresponding to the secondary porosity of the samples, indicating that the active sites are mainly the Ti centers located on the latter with little contribution of the Ti atoms existing within the zeolitic micropores. This remarkable catalytic activity is accompanied by both high selectivities towards the epoxide and oxidant efficiencies.

\section{Acknowledgments}

We want to thank "Ministerio de Educación y Ciencia" (Spain, project CICYT CTQ2005097078) for its financial support to this research. 


\section{References}

[1] D. W. Breck, Zeolite Molecular Sieves (John Wiley \& Sons, inc., New York, 1974).

[2] A. Corma, M. S. Grande, V. Gonzalez-Alfaro and A. V. Orchille, J. Catal. 159 (1996) 357.

[3] A. Corma, V. Fornés, M. T. Navarro and J. Pérez-Pariente, J. Catal. 148 (1994) 569.

[4] M. Hartmann, Angew. Chem. Int. Ed. Engl. 43 (2004) 5880.

[5] J. Pérez-Ramirez, C. H. Christensen, K. Egeblad, C. H. Christensen and J. C. Groen, Chem. Soc. Rev. 37 (2008) 2530.

[6] S. Van Dock, A. H. Jansen, J. H. Bitter and K. P. Jong, Catal. Rev. 45 (2003) 297.

[7] I. Schmidt, A. Boisen, E. Gustavsson, K. Stahl, S. Pehrson, S. Dahl, A. Carlsson and C. J. H. Jacobsen, Chem. Mater. 13 (2001) 4416.

[8] B. T. Holland, L. Abrams and A. Stein, J. Am. Chem. Soc. 121 (1999) 4308.

[9] M. Choi, H. S. Cho, R. Srivastava, C. Venkatesan, D. H. Choi and R. Ryoo, Nature Mater. 5 (2006) 718.

[10] A. Dong, Y. Wang, Y. Tang, N. Ren, Y. Zhang, Y. Yue and Z. Gao, Adv. Mater. 14 (2002) 926.

[11] M. W. Anderson, S. M. Holmes, N. Hanif and C. S. Cundy, Angew. Int. Ed. 39 (2000) 2707.

[12] A. Karlsson, M. Stöcker and R. Schmidt, Microporous Mesoporous Mater. 27 (1999) 181.

[13] F. S. Xiao, L. Wang, C. Yin, K. Lin, Y. Di, J. Li, R. Xu, D. Su, R. Schlogl, T. Yokoi and T. Tatsumi, Angew. Chem. Int. Ed. 45 (2006) 3090. 
[14] M. Choi, H. S. Cho, R. Srivastava, C. Venkatesan, D. Choi and R. Ryoo, Nat. Mater. 5 (2006) 718.

[15] A. Corma, V. Fornés, J. M. Guil, S. Pergher, Th. L. M. Maesen and J. G. Buglass, Microporous and Mesoporous Mater. 38 (2000) 301.

[16] D. P. Serrano, J. Aguado, J. M. Escola, J. M. Rodríguez and A. Peral, Chem. Mater. 8 (2006) 2462.

[17] J. Aguado, D. P. Serrano and J. M. Rodriguez, Microporous and Mesoporous Mater. 115 (2008) 504 .

[18] J. Aguado, D. P. Serrano, J. M. Escola and A. Peral, J. Anal. Appl. Pyrolysis (2009) 352.

[19] M. Taramasso, G. Perego and B. Notari, US Pat. 4410501 (1983).

[20] B. Notari, Adv. Catal. 42 (1996) 253.

[21] R. A. Sheldon, M. Wallau and U. Schuchardt, Angew. Chem. Int. Ed. Engl. 36 (1997) 1144.

[22] C. B. Khouw and M.E. Davis, J. Catal. 151 (1995) 77.

[23] A. Bhaumik and T. Tatsumi, J. Catal. 176 (1998) 305.

[24] L. Y. Chen, G. K. Chuah and S. Jaenicke, Catal. Lett. 50 (1998) 107.

[25] I. Schmidt, A. Krogh, K. Wienberg, A. Carlsson, M. Brorson and C. J. H, Jacobsen, Chem. Commun. 21 (2000) 2157.

[26] Y. Fang and H. Hu, Catal. Commun. 8 (2007) 817.

[27] D. P. Serrano, M. Uguina, G. Ovejero, R. van Grieken and M. Camacho, Microporous Mater. 4 (1995) 273.

[28] D. P. Serrano and R. Van Grieken, J. Mater. Chem. 11 (2001) 2391. 
[29] M. R. Boccuti; K. M. Rao; A. Zecchina; G. Leofanti and G. Petrini, Stud. Surf. Sci. Catal. 48 (1989) 133.

[30] L. Bonneviot, D. Trong On and A. Lopez, J. Chem. Soc. Chem. Commun. (1993) 685.

[31] T. Blasco, A. Corma, M. T. Navarro and J. Perez Pariente, J. Catal. 156 (1995) 133. 
Table 1. Crystallization yield and composition of the TS-1 samples.

\begin{tabular}{|c|c|c|c|}
\hline Sample & $\begin{array}{c}\text { Starting } \\
\text { material }\end{array}$ & $\begin{array}{c}\text { Crystallization } \\
\text { Yield }(\%)\end{array}$ & $\begin{array}{c}\text { Ti content } \\
\text { (wt \%) }\end{array}$ \\
\hline TS-1 (LG-REF) & LG & 51.8 & 0.97 \\
\hline TS-1 (LG-PC) & LG & 41.6 & 1.05 \\
\hline TS-1 (LG-8 \%) & LG & 64.8 & 1.09 \\
\hline TS-1 (XG-REF) & XG & 70.4 & 1.18 \\
\hline TS-1 (XG-5 \%) & XG & 74.1 & 1.00 \\
\hline
\end{tabular}


Table 2. Textural properties of the TS-1 samples estimated from the Ar adsorption isotherm by applying the NL-DFT method.

\begin{tabular}{|cccccc|}
\hline Sample & Sвет $\left(\mathrm{m}^{2} / \mathrm{g}\right)$ & Szm $\left._{\text {zm }} / \mathrm{g}\right)$ & SsP $\left(\mathrm{m}^{2} / \mathrm{g}\right)$ & $\mathrm{V}_{\text {zm }}\left(\mathrm{cm}^{3} / \mathrm{g}\right)$ & $\mathrm{V}_{\text {sP }}\left(\mathrm{cm}^{3} / \mathrm{g}\right)$ \\
\hline TS-1 (LG-REF) & 446 & 362 & 84 & 0.222 & 0.075 \\
TS-1 (LG-PC) & 479 & 347 & 132 & 0.213 & 0.336 \\
TS-1 (LG-8 \%) & 606 & 258 & 349 & 0.158 & 0.290 \\
TS-1 (XG-REF) & 469 & 416 & 53 & 0.222 & 0.075 \\
TS-1 (XG-5 \%) & 564 & 294 & 270 & 0.157 & 0.192 \\
\hline
\end{tabular}

ZM: zeolitic micropores; SP: secondary porosity 
Table 3. Catalytic activity of TS-1 samples in 1-octene epoxidation with $\mathrm{H}_{2} \mathrm{O}_{2}$.

\begin{tabular}{|ccccc|}
\hline Sample & SsP $\left(\mathrm{m}^{2} / \mathrm{g}\right)$ & $\mathrm{X}_{\text {1-OCTENE }}(\%)$ & $\mathrm{TOF}\left(\mathrm{h}^{-1}\right)$ & $\mathrm{H}_{2} \mathrm{O}_{2}$ efficiency $(\%)$ \\
\hline TS-1 (LG-REF) & 84 & 11.4 & 18.6 & 65.5 \\
TS-1 (LG-PC) & 132 & 5.5 & 10.1 & 53.9 \\
TS-1 (LG-8 \%) & 349 & 3.4 & 7.1 & 64.4 \\
TS-1 (XG-REF) & 53 & 12.4 & 20.3 & 62.4 \\
TS-1 (XG-5 \%) & 270 & 4.5 & 8.1 & 53.5 \\
\hline
\end{tabular}

Reaction conditions: $60^{\circ} \mathrm{C}, 3 \mathrm{~h}$, (olefin $/ \mathrm{H}_{2} \mathrm{O}_{2}$ )MOLAR $=2,0.4 \mathrm{~g}$ catalyst 
Table 4. Catalytic activity of TS-1 samples in olefin epoxidation with TBHP

\begin{tabular}{|c|c|c|c|c|c|c|c|}
\hline \multirow[b]{2}{*}{ Sample } & \multirow[b]{2}{*}{$\begin{array}{c}\text { Ssp } \\
\left(\mathrm{m}^{2} / \mathrm{g}\right)\end{array}$} & \multicolumn{3}{|c|}{ 1-octene epoxidation } & \multicolumn{3}{|c|}{ Cyclohexene epoxidation } \\
\hline & & $\begin{array}{c}\text { X-OCTENE }_{\text {1-OC }} \\
(\%)\end{array}$ & $\begin{array}{l}\text { TOF } \\
\left(\mathrm{h}^{-1}\right)\end{array}$ & $\begin{array}{c}\text { TBHP } \\
\text { efficiency (\%) }\end{array}$ & $\begin{array}{c}\text { X XYCLOHEXENE } \\
(\%)\end{array}$ & $\begin{array}{l}\text { TOF } \\
\left(\mathrm{h}^{-1}\right)\end{array}$ & $\begin{array}{c}\text { TBHP } \\
\text { efficiency (\%) }\end{array}$ \\
\hline TS-1 (LG-REF) & 84 & 6.7 & 11.9 & 91.5 & 22.0 & 55.0 & 92.0 \\
\hline TS-1 (LG-PC) & 132 & 14.8 & 23.8 & 90.8 & 36.5 & 84.3 & 78.6 \\
\hline TS-1 (LG-8 \%) & 349 & 42.1 & 82.9 & 90.0 & 85.3 & 234.7 & 91.9 \\
\hline TS-1 (XG-REF) & 53 & 4.2 & 7.0 & 90.2 & 23.8 & 54.5 & 98.7 \\
\hline TS-1 (XG-5 \%) & 270 & 26.4 & 47.8 & 90.6 & 65.2 & 159.0 & 90.3 \\
\hline
\end{tabular}

Reaction conditions: $10{ }^{\circ} \mathrm{C}, 3 \mathrm{~h}$, (olefin/TBHP)MOLAR $=1.25,0.2 \mathrm{~g}$ catalyst 


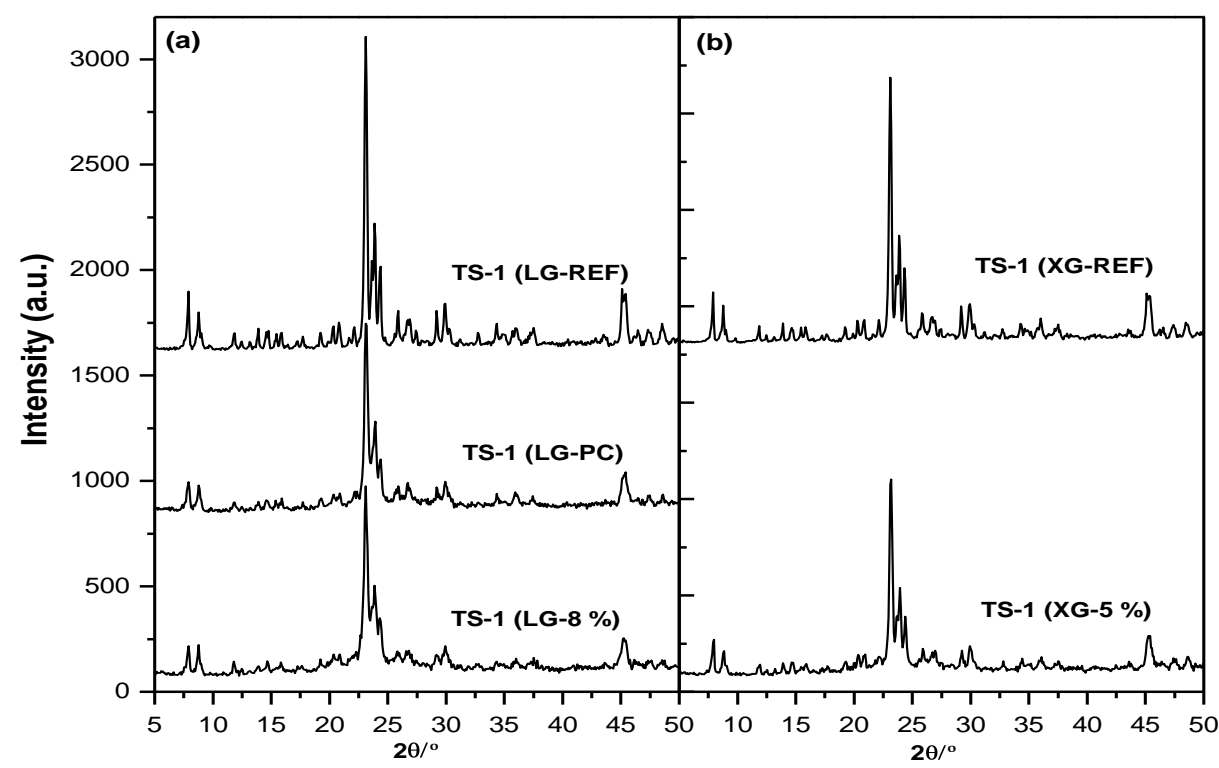

Figure 1. XRD patterns of as-synthesized TS-1 samples prepared from (a) liquid gels and (b) amorphous $\mathrm{SiO}_{2}-\mathrm{TiO}_{2}$ xerogels. 


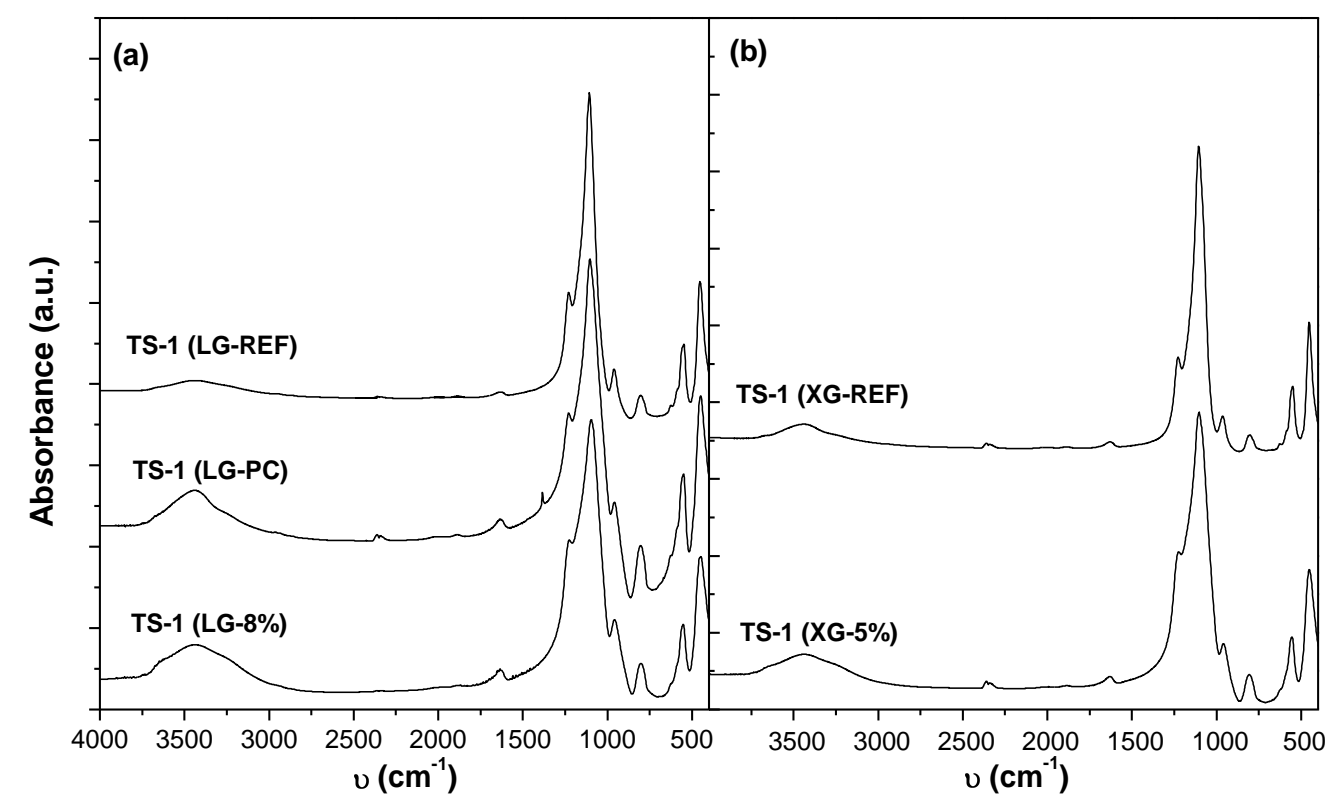

Figure 2. FT-IR espectra of calcined TS-1 samples prepared from (a) liquid gels and (b) amorphous $\mathrm{SiO}_{2}-\mathrm{TiO}_{2}$ xerogels. 


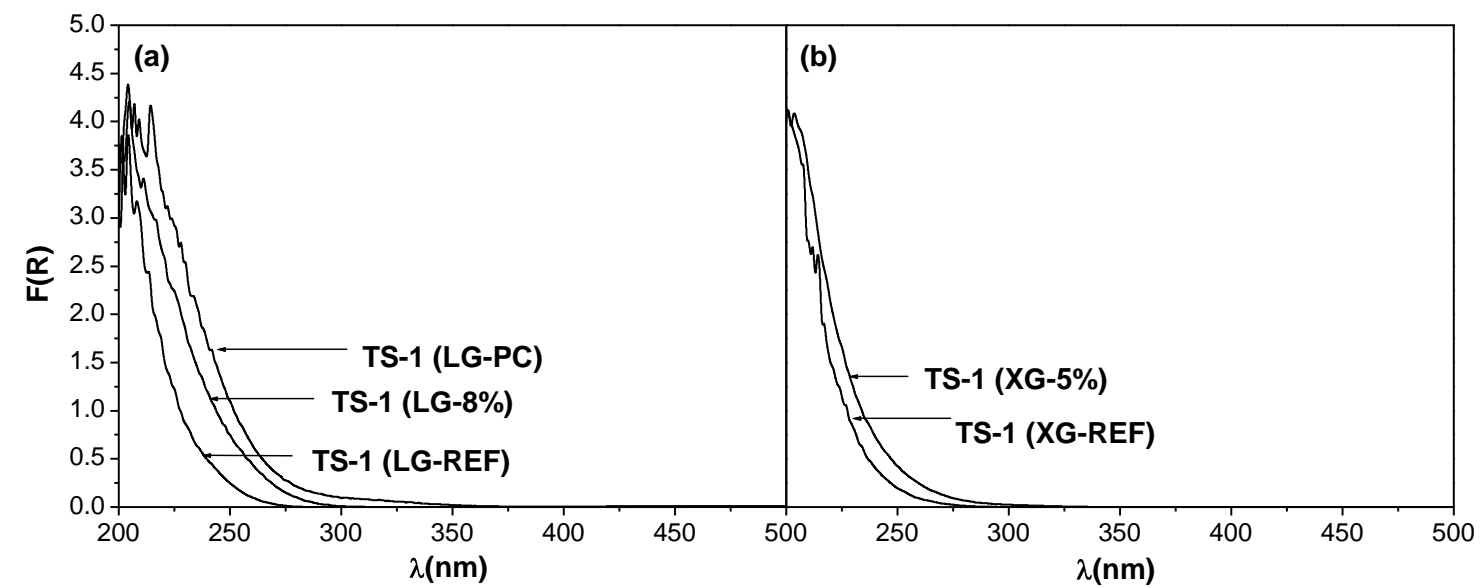

Figure 3. DR UV-Vis spectra of calcined TS-1 samples prepared from (a) liquid gels and (b) amorphous $\mathrm{SiO}_{2}-\mathrm{TiO}_{2}$ xerogels. 


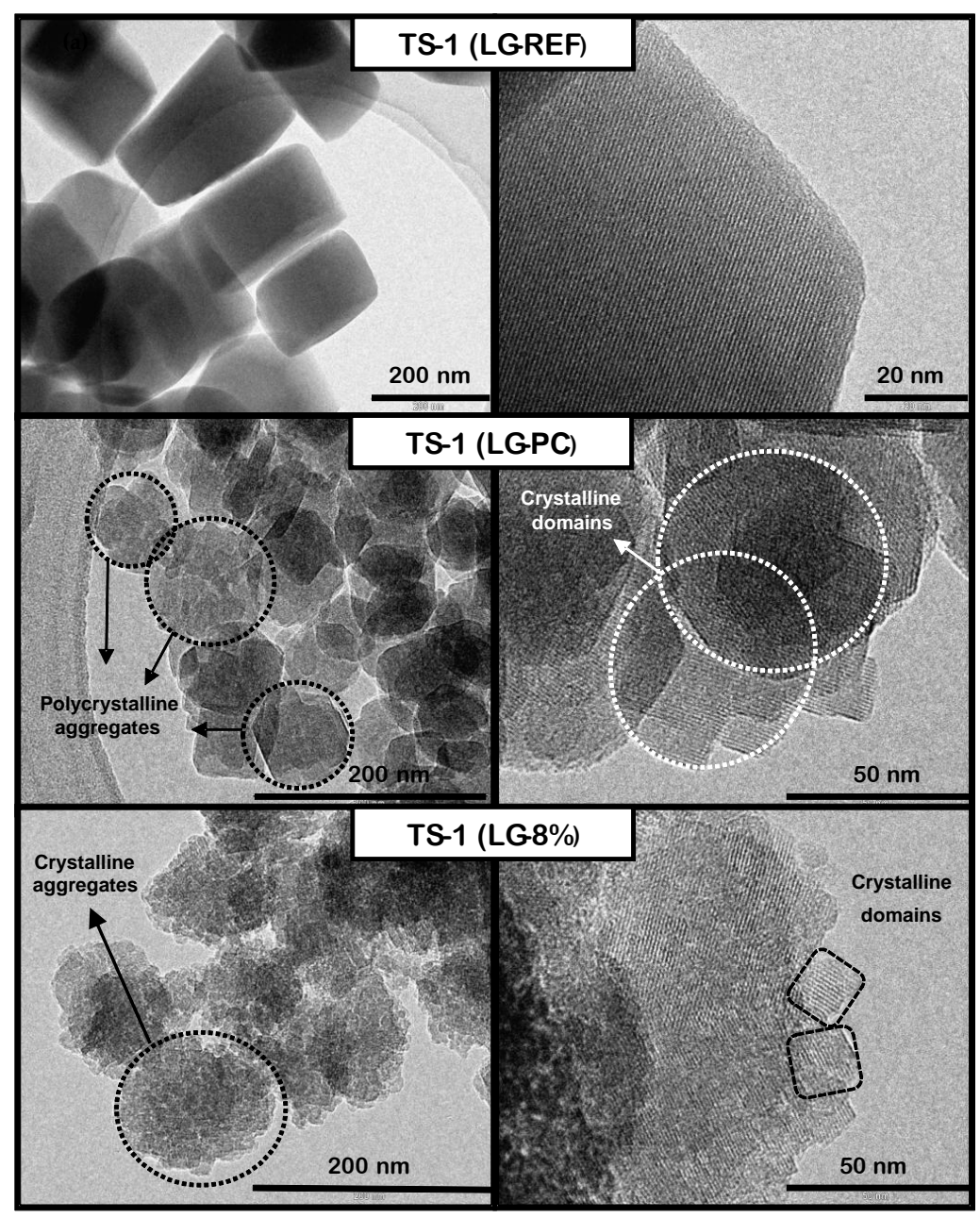

Figure 4. TEM micrographs of TS-1 samples prepared from liquid gels. 


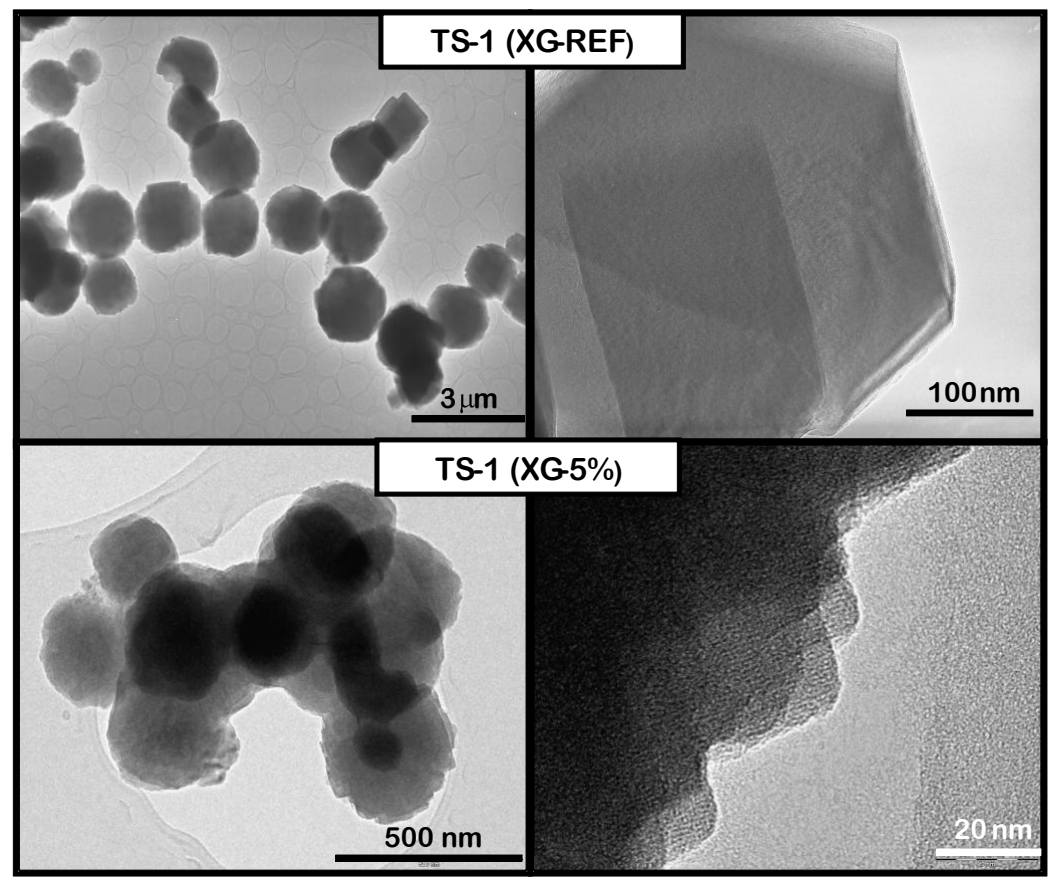

Figure 5. TEM micrographs of TS-1 samples prepared from amorphous $\mathrm{SiO}_{2}-\mathrm{TiO}_{2}$ xerogels. 


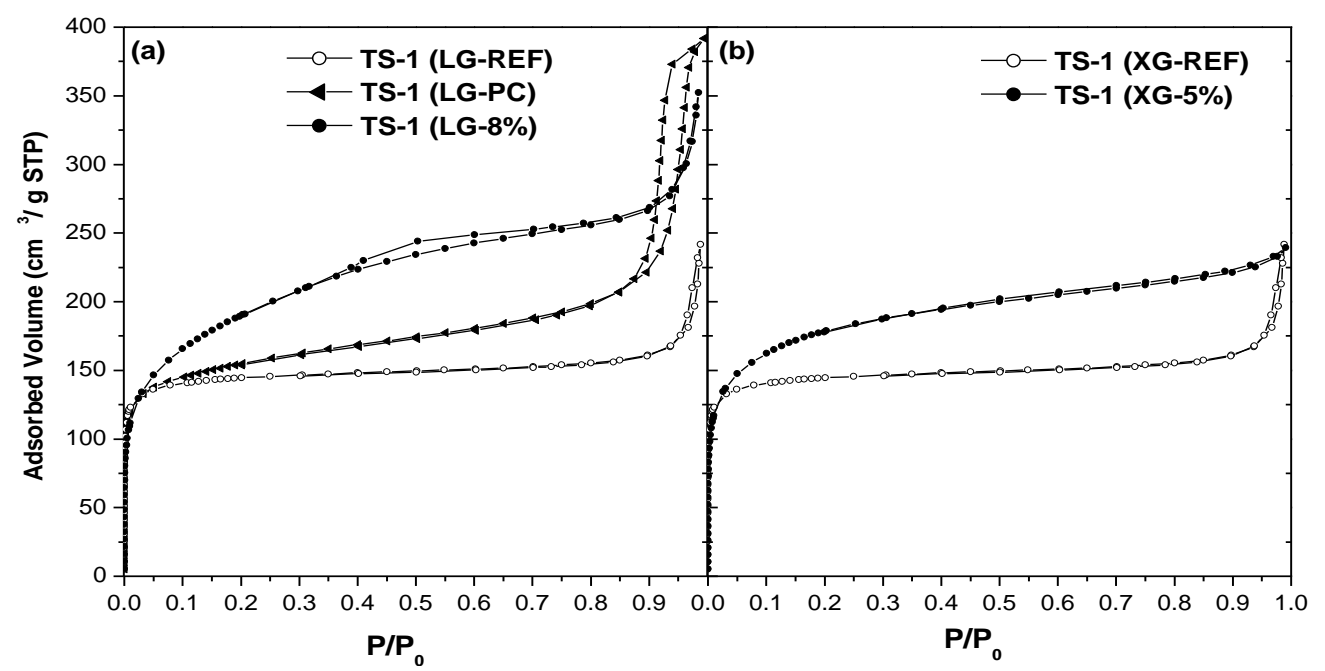

Figure 6. Ar adsorption-desorption isotherms at $87.3 \mathrm{~K}$ of calcined TS-1 samples prepared from (a) liquid gels and (b) amorphous $\mathrm{SiO}_{2}-\mathrm{TiO}_{2}$ xerogels. 

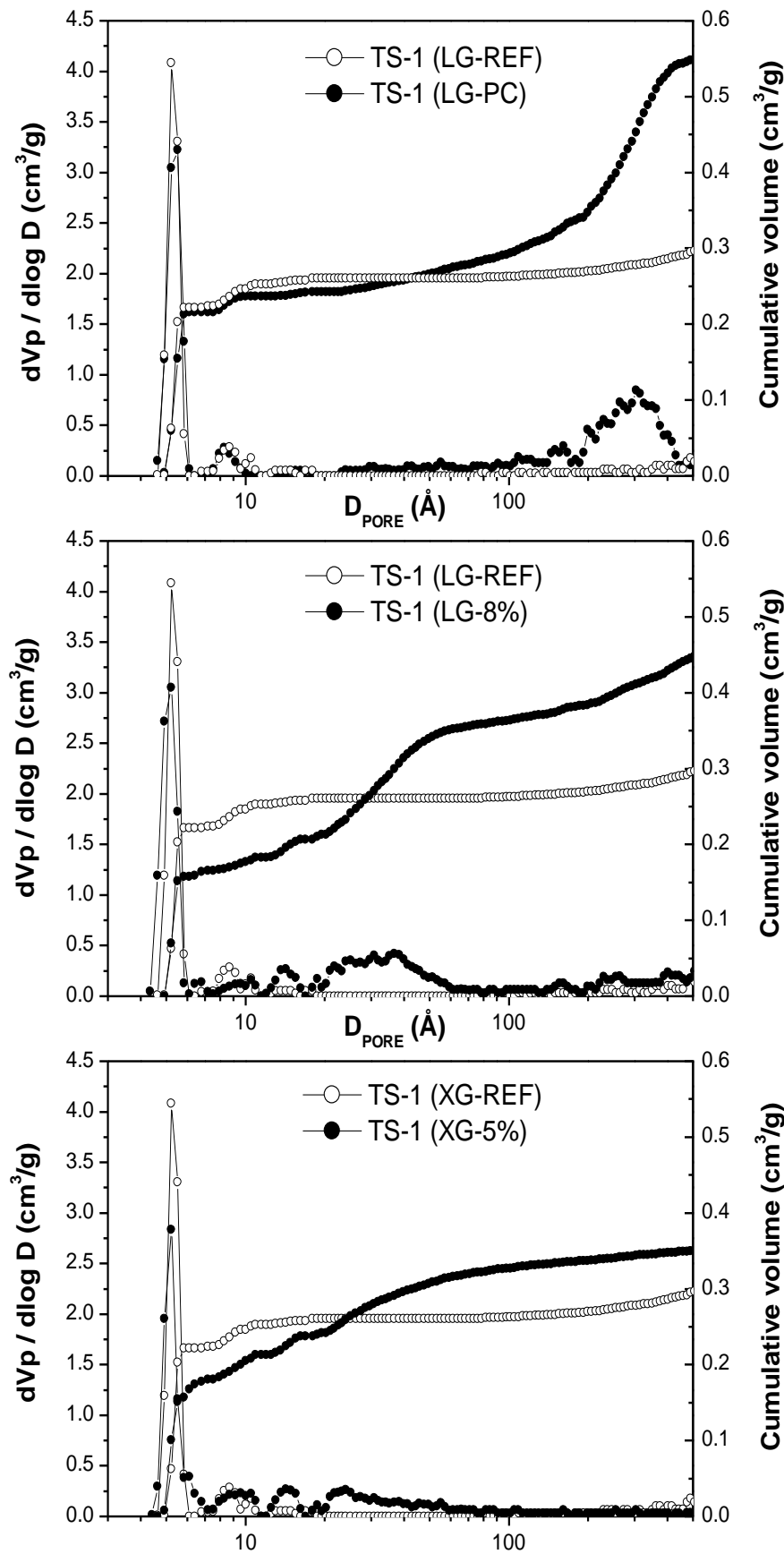

Figure 7. Cumulative pore volume and pore size distribution of the TS-1 samples estimated by applying the NL-DFT model. 


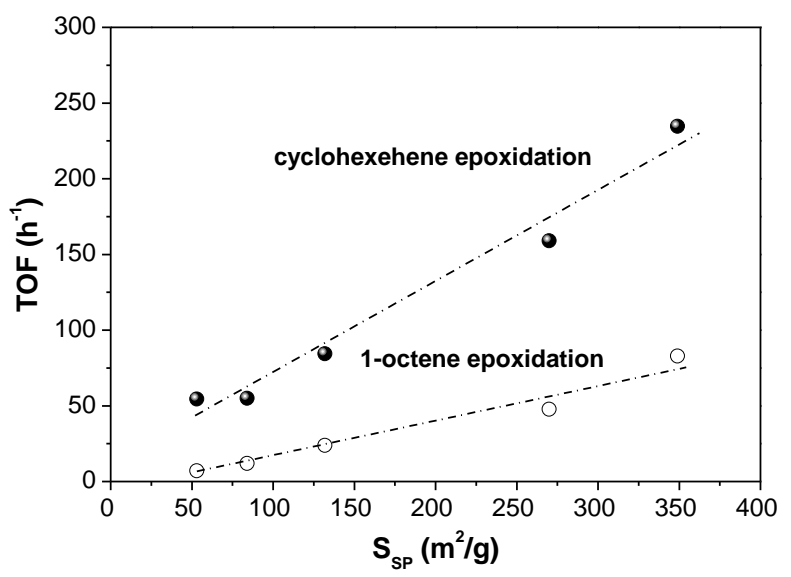

Figure 8. Variation of the catalytic activity (TOF) in olefin epoxidation with the surface area related to the secondary porosity of the TS-1 samples. 